\title{
Defensa de la competencia en la Argentina: aspectos constitucionales y vinculación con el derecho de usuarios y consumidores
}

\section{Antitrust in Argentina: Constitutional Aspects Linked to the Right of Users and Consumers}

Carlos Eduardo Tambussi* http://dx.doi.org/10.21503/lex.v12i14.618

* Abogado, Universidad de Buenos Aires (1991. Auditor legal de la Administración de Parques Nacionales (2007-2010). Procurador Adjunto de Asuntos Patrimoniales y Fiscales del Gobierno de la Ciudad Autónoma de Buenos Aires (2010-2012). Profesor adjunto regular en la Universidad de Buenos Aires, Facultad de Derecho, asignatura de Derechos Humanos y Garantías. Presidente de la Comisión de Derechos del Consumidor de la Asociación de Abogados de Buenos Aires. Correo electrónico: cetambu@uolsinectis. com.ar 


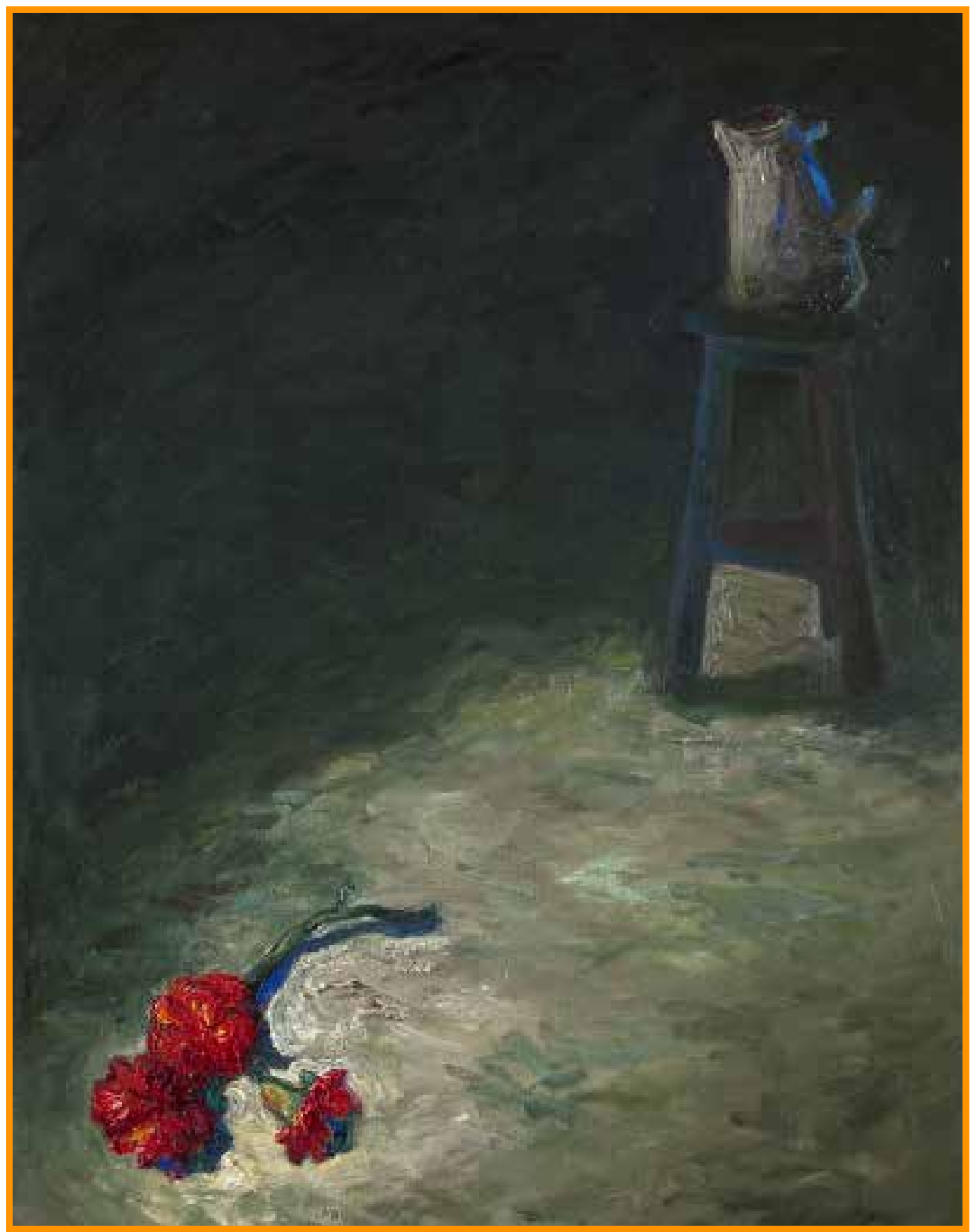

Estaciones del alma. Óleo sobre tela $(120 \times 90 \mathrm{~cm})$. 


\section{RESUMEN}

En la Argentina, la defensa de la competencia es un valor constitucionalmente protegido y de directa relación con la protección de usuarios y consumidores, al estar directamente relacionada con el resguardo de la libre elección, el derecho a la información y a la protección de sus intereses económicos. El marco competitivo pertenece a las políticas públicas y protege fundamentalmente el acceso al mercado a la vez que la permanencia en el mismo de los proveedores de bienes y servicios. Para garantizar la vigencia de estos valores, el Estado regulador debe establecer una agencia independiente de las circunstancias políticas de turno, de forma de asegurar el debido control del desenvolvimiento del mercado, para lo que resulta necesario implementar mecanismos de garantías que permitan la participación de los consumidores y sus organizaciones.

Palabras clave: competencia, consumidores y usuarios, mercado, regulación.

\section{ABSTRACT}

In Argentina, the antitrust is a constitutionally value protected and directly related to the protection of users and consumers, to be directly related to the receipt of free choice, the right to information and the protection of their economic interests. The competitive framework belongs to public policy and fundamentally protects market access while staying in the same providers of goods and services. To ensure the validity of these values, the regulatory State must establish an independent agency of the political circumstances of the moment, in order to ensure proper control of the development of the market, for which it is necessary to implement mechanisms of guarantees to enable the participation of consumers and their organizations.

Key words: competition, consumers and users, market, regulation. 



\section{ASPECTOS CONSTITUCIONALES}

Constitución de la Nación Argentina (reformada en 1994):

Artículo 42 (parte pertinente). Los consumidores y usuarios de bienes y servicios tienen derecho, en la relación de consumo, a la protección de su salud, seguridad e intereses económicos; a una información adecuada y veraz; a la libertad de elección, y a condiciones de trato equitativo y digno.

Las autoridades proveerán a la protección de esos derechos, a la educación para el consumo, a la defensa de la competencia contra toda forma de distorsión de los mercados, al control de los monopolios naturales y legales, al de la calidad y eficiencia de los servicios públicos, y a la constitución de asociaciones de consumidores y de usuarios.

El constituyente de 1994 ha incorporado como valor y política de Estado, con la perspectiva de perdurabilidad de los textos constitucionales, este derecho a nuestra Carta Magna, llevándolo a su más alta consideración, con las consecuencias del reconocimiento expreso y las particularidades en cuanto a la legitimación activa para la defensa judicial de los asuntos de consumidores y usuarios y la defensa de la competencia, habiendo quedado expresamente plasmada la trascendencia que ha tenido para el constituyente y para la ciencia jurídica la elevación a rango constitucional de la protección de la competencia, un derecho con verdadero impacto en el mundo del consumo, ya que a la vez que resulta un instrumento regulador, importa un resguardo de la economía de mercado, al proteger contra las distorsiones monopólicas y propiciando el libre acceso al mismo. Aunque visto y hasta considerado en los ámbitos académicos como un derecho atinente a prácticas interempresarias o al ejercicio del poder de policía del Estado, la protección del acceso y permanencia en el mercado también beneficia a los consumidores, "pues la falta de libre competencia coloca a estos en una situación de mayor inferioridad". ${ }^{1}$

Domingo Pigretti. "La nueva ley de defensa de la competencia", ED 98-857, citado por Juan M. Farina. Contratos comerciales modernos. Buenos Aires: Astrea, 1994, p. 257. 
La regulación del mercado es un mecanismo de carácter público, que excede el ámbito exclusivamente contractual o el de los usos y costumbres comerciales, para atender a una visión estructural que se conjuga con otros instrumentos estatales de ordenación, como los que reglan el funcionamiento de la Bolsa de Comercio (Comisión Nacional de Valores) o el Código Aduanero, mediante el cual la política económico-arancelaria puede utilizarse para proteger la producción local de la competencia extranjera, herramienta esta que ha tenido distintos usos según la ideología que la dirija, según los tiempos, según los hombres.

\section{SU INFLUENCIA EN EL DERECHO DE USUARIOS Y CONSUMIDORES}

Lo que suceda en el mercado es de directa incidencia en los derechos del consumidor, y en definitiva, en su suerte. En el necesario abordaje interdisciplinario del fenómeno del consumo, la visión microeconómica o macroeconómica del ámbito en que se lleva a cabo la relación de consumo es imposible de soslayar para un buen diagnóstico, para la correcta aplicación de la legislación y la medición de sus consecuencias.

La cuestión del análisis jurídico de la defensa de la competencia aparece como una herramienta imprescindible frente a las ideas siempre presentes en los ámbitos de pensamiento económico, donde la corriente neoliberal no exhibe demasiado entusiasmo en la persecución de los abusos del poder del mercado. ${ }^{2}$ Para esta teoría, ese ámbito inmaterial llamado mercado (ahora con actores cada vez más "anónimos" y transnacionales) es el óptimo asignador de recursos, y por ende es esencial e ideológicamente refractario a toda intervención del Estado en este aspecto.

Nos pronunciamos, en contrapartida, por un Estado que proteja las condiciones de competencia, justamente para la defensa de los consumidores y para que el mismo mercado pueda continuar funcionando, encontrando "un equilibrio aceptable entre la libertad económica y la obligación del Estado de mantener criterios de justicia en la distribución”. ${ }^{3}$

Por eso resulta necesario redefinir el rol estatal, ${ }^{4}$ que no puede volver a ser el activo directo de otros tiempos en la mayoría de los casos, pero que tiene la función irrenunciable de vigilancia del apropiado funcionamiento mercantil, evitando las concentraciones de poder económico tendientes al abuso y al privilegio. Más aún, en estructuras económicas como la de nuestra Argentina, donde la conformación monopólica u oligopólica del mercado en diferentes rubros y la tendencia a la concentración de muchas actividades en pocas manos coadyuvan

2 Claudio Lutzky. "El orden económico, las formas del mercado y la defensa de la competencia". Temas de Derecho Industrial $y$ de la Competencia, 4 (2000), pp. 93-108.

Ibidem.

4 Fargosi, citando a W. Ropke afirma que "es de un liberalismo trasnochado sostener que la situación deseable de la libre competencia se mantenga por sí misma por la vía de una abstención del Estado”. 
a conformar un factor determinante en desmedro de los derechos de los consumidores y usuarios, que se traslada a muchos otros aspectos (v. gr. laboral, fiscal).

La libertad de comercio consagrada por la Constitución Nacional ${ }^{5}$ implica a su vez libertad de mercado, en tanto libre acceso de productores y consumidores, siendo esa la ratio legis de su consideración legal en una norma protectoria del valor competencia.

El mercado es un espacio en el que convergen distintos agentes para satisfacer necesidades mediante integración de la oferta y la demanda. De esa manera, quienes compran y quienes venden pueden satisfacer sus objetivos y necesidades y obtener ganancias sin necesidad de excluir a otros ni a costa de otros. El acceso al mercado es entonces un bien jurídicamente protegible, y en esa virtud los agentes deben actuar en forma respetuosa y leal hacia competidores, contratantes y clientes, y quienes tengan posición privilegiada en el mercado no deben usarla para aprovecharse de ella o para eliminar adversarios.

Sobre estos elementos debe velar el Estado, detectando monopolios, posiciones de dominio o acuerdos que anulen la competencia, en la inteligencia que el mercado se rige también en algunos aspectos como el sistema democrático en el que debe haber libre ingreso y participación, ausencia de discriminación e igualdad de oportunidades, todos valores de raigambre constitucional.

La falta de libertad de mercado trae aparejadas una serie de consecuencias negativas para los consumidores. Cuando existen concentraciones monopólicas que desarrollan prácticas anticompetitivas, se restringe su libertad de elegir y actuar. La libre elección es el derecho de acceder a una variedad de productos y servicios en determinadas condiciones de calidad, a precios justos y razonables, de modo que el consumidor acceda a la más amplia variedad al menor costo. Y mediante el control del desenvolvimiento de las concentraciones, se protegen también los intereses económicos de los consumidores, ya que en posiciones monopólicas los precios se fijan sin consideración a competidor alguno, aspecto que cobra mayor gravedad en productos de primera necesidad y/o no sustituibles fácilmente. Por ello, es un valor tutelado por la defensa de la competencia el llamado interés económico general, que en cada consumidor se particulariza.

También, el derecho de acceso al consumo se relaciona con la existencia de un ámbito competitivo, ya que un mercado que no presenta estas características genera dificultades e impedimentos para la obtención de bienes y servicios a la mayoría de la población. La Declaración de Derechos Fundamentales de los Consumidores del Mercosur, aprobada en el marco de la XIX Reunión del Consejo del Mercado Común, consagra el "derecho de acceso

\footnotetext{
Sin renegar de la libertad de comercio, el texto constitucional de 1853/60 contenía el Artículo 67 inciso 16, la llamada
} "cláusula del progreso" que fue la llave maestra de la convalidación de la intervención económica del Estado. 
al consumo con libertad de elección, sin discriminaciones ni arbitrariedades, tendiéndose a asegurar la existencia de una libre competencia que permita una oferta variada a precios competitivos".

Además, la competencia se relaciona con el derecho a la información del consumidor, que le permite conocer lo que se produce y comercializa, y quiénes lo ofrecen y cómo. Por ese motivo, la publicidad de bienes y servicios es una manifestación del decurso competitivo en el mercado.

El efecto mediato de la defensa de la competencia es la defensa del consumidor, propiciando la transparencia de mercado y controlando las distorsiones que afectan a la distribución, condiciones de venta, calidad y precios de bienes y servicios. "A mayor división o dispersión del poder de mercado, menor acumulación de poder individual para dominar, y, entonces, las posibilidades de engaño o de abuso a los consumidores o competidores tienden a ser inexistentes". 6

Por su parte, el artículo tercero de la Ley 24.240 de Defensa del Consumidor establece que las disposiciones de esa ley se integran con las normas generales y especiales aplicables a las relaciones jurídicas antes definidas, en particular las de defensa de la competencia y lealtad comercial. Se forma así un sistema integral para la protección de usuarios y consumidores. La integración de la Ley de Defensa del Consumidor, con sus conceptos amplios y legitimadores de consumidor, proveedor y relación de consumo, se da también con numerosas normas de carácter administrativo nacional, provincial y municipal, con leyes específicas como el Código Alimentario Nacional (Ley 18.284) o el Plan Médico Obligatorio (para citar algunos ejemplos), resoluciones de entes reguladores, normas correspondientes a servicios determinados (hotelería, turismo, transporte, etcétera), y desde luego con las normas generales del Código Civil ${ }^{7}$ y Código de Comercio, constituyendo el plexo protectorio aplicable bajo sus principios, en especial el de norma más favorable al consumidor.

De ahí lo que los autores entienden como el "carácter multidisciplinario propio del estatuto del consumidor", dado que este se aplica a toda relación jurídica regulada por normas en la que exista relación de consumo, en una noción de "sistema integral de protección" o "microsistema", como se señala en doctrina y que nosotros llamamos "régimen tuitivo consumidor".

Por último, y en relación a la política de servicios públicos, la defensa de la competencia es un instrumento de política pública que tiene por objetivo que el resultado del funcionamiento

6 Ernesto Cionfrini. "La protección de los mercados y la competencia en la Constitución Nacional”. Doctrina Judicial, 2 (2002), p. 305.

7 Ver, por ejemplo, el artículo 18 de La Ley 24.240, que dispone, con relación a los vicios redhibitorios, la aplicación del artículo 2178, Código Civil, y la no oponibilidad del artículo 2170. 
de los mercados se asemeje a uno del tipo competitivo, al evitar que agentes que operan en el mismo, o en un sector determinado, abusen de posiciones de dominio o hagan fusiones de empresas que fomenten esas conductas. Para que esto sea posible, debe existir correlación entre la política regulatoria de servicios públicos y la defensa de la competencia, y las decisiones regulatorias deben ser revisadas por las autoridades de defensa de la competencia. Un paso adelante ha sido el artículo 16 de la Ley de Defensa de la Competencia (25.156), incorporado en 1999, que establece que cuando una concentración económica involucra a empresas sujetas al control de entes reguladores de servicios públicos, el Tribunal de Defensa de la Competencia debe pedir informes al ente respectivo sobre el impacto en el mercado de la unión y sobre el cumplimiento de los requisitos del marco regulatorio.

\section{ALCANCE CONSTITUCIONAL DE LA DEFENSA DE LA COMPETENCIA EN LA ARGENTINA}

Acordamos, luego de las reflexiones anteriores, que si bien la Carta Magna Nacional ${ }^{8}$ adopta la economía de mercado como ámbito económico, ha establecido como política de Estado9 el valor de defender la libre competencia a través de la regulación, punitiva o preventiva, en su resguardo. Y en materia de garantías, el Art. 43 de la Constitución incluye la posibilidad de ejercicio de la acción de amparo para defender estos derechos. ${ }^{10}$ En suma, el mercado es libre, pero no se ha librado de una política al respecto.

Si bien desde el punto de vista conceptual la Defensa de la Competencia y la Defensa del Consumidor son diferentes, atento el carácter interempresarial de la segunda, en la primera hay una implicación indirecta de los derechos del consumidor, que es protegido cuando se evitan concentraciones económicas que le pueden traer perjuicios y afectar el principio de libre elección. La libertad de mercado y la defensa de la competencia son garantías constitucionales e institucionales destinadas a proteger finalidades de naturaleza pública, para satisfacer el bienestar general.

Esa libertad de mercado puede coexistir con algunas formas monopólicas, que pueden ser de origen natural (en aquellos casos donde dadas las condiciones en que se proveen bienes o

8 También el artículo 46 de la Constitución de la Ciudad Autónoma de Buenos Aires establece que la ciudad garantiza "la defensa de los consumidores y usuarios en la relación de consumo, contra la distorsión de los mercados y el control de los monopolios que los afecten".

9 Aun antes de la Reforma de 1994, cuando ciertos sectores predicaban la histórica e inconmovible adhesión al liberalismo económico de la Constitución de 1853-60, la famosa "Cláusula del Progreso" del viejo artículo 67 inciso 16 (actual artículo 75 inciso 18) había servido como fundamento jurídico para el accionar del Estado, sosteniendo tanto su política reguladora, como directamente intervencionista.

10 "Podrán interponer esta acción contra cualquier forma de discriminación y en lo relativo a derechos que protegen al ambiente, a la competencia, al usuario y al consumidor, así como a los derechos de incidencia colectiva en general, el afectado, el Defensor del Pueblo y las asociaciones que propendan a esos fines, registradas conforme a la ley, la que determinará los requisitos y formas de su organización”. 
se prestan servicios es imposible la concurrencia — por ejemplo, el sistema de saneamiento y cloacas-) o legal (los monopolios creados por el Estado, por razones de política económica). ${ }^{11}$

El Artículo 42 de la Constitución Nacional protege los valores antes descritos, que se asocian íntimamente con la protección de los derechos del consumidor. Ha establecido la protección revestida de la supralegalidad de un texto constitucional, ha fijado la política de la Nación Argentina respecto de la atención del comportamiento del mercado. ${ }^{12}$

En su consecuencia, la Constitución establece un sistema de:

a) Derechos: en las relaciones de consumo y competencia.

b) Deberes: en el cumplimiento de las obligaciones para con el Estado.

c) Garantías: legitimación para el amparo judicial, no como defensa individual sino como instrumento de ordenación económica y control del funcionamiento global de los mercados.

El gran desafío consiste en conjugar la efectividad de la vigencia de los derechos protegidos, con la voluntad política del Estado en aplicar una determinada praxis económica.

\section{FUNCIÓN SOCIAL DE LA DEFENSA DE LA COMPETENCIA}

Las cuestiones de defensa de la competencia no se reducen al área jusprivatista, económicoempresarial. Entendemos que no hay que plantear el tema competencia como de disputa entre empresas, sino que debe estudiárselo como un mecanismo de carácter público. Esto implica salir del ámbito exclusivamente contractual o de los usos y costumbres comerciales, para ir al estudio y análisis que parta de una visión estructural del mercado, y no necesariamente de su aceptación. Puede ser (y lo sabemos positivamente) que los usos y costumbres comerciales sean malos, perjudiciales al interés general.

Los mercados competitivos, fluidos y transparentes requieren un contexto apto para ello, con exigencias generales que pasen la prueba de la razonabilidad, con lo que se requiere la implementación de mecanismos de control adecuados y eficaces.

11 “Serán 'monopolios naturales' aquellos en los cuales, dadas las condiciones en que deberán hacerse la provisión de bienes y servicios, no resulta posible la concurrencia de otros prestadores en competencia. Es una situación típica que es habitual por ejemplo en la prestación de servicios domiciliarios como de saneamiento, en los que, dada la complejidad técnica de las instalaciones, no permite la concurrencia de más de un prestador en una determinada área. Estos no son punibles en sí mismos, pero pueden originar abusos sancionables. También puede darse el caso de 'monopolios legales' en los cuales no se presentan los inconvenientes técnicos anteriores, son establecidos por el Estado, muchas veces fundamentándolos en economía de escala". [Marcela Basterra. "La defensa de la competencia en la Constitución Argentina. El artículo 42 y su ley reglamentaria 25.136”. Doctrina Judicial (2003-2), p. 833.]

12 Aquellos que consideran al mercado obra del azar con base en el albedrío de los operadores económicos, lo que sería equivalente a una "selva económica", prevaleciendo la ley del más fuere o el más predador, rechazan la competencia condenándola precisamente por considerarla causal del salvajismo mercantil. Por lo tanto, rechazan la utilización de la acción de los poderes públicos para la implantación, fijación y exigencia de las leyes de defensa de la competencia. 
El mercado competitivo, de esa manera, quedará configurado como el ámbito de libertad que resta al margen de los deberes u obligaciones (verbigracia, pagar impuestos), descontando las distintas prohibiciones o regulaciones que se establezcan.

El espacio que queda es el ejercicio de los derechos individuales garantizado por la Constitución Nacional, sujeto a las leyes que reglamenten su ejercicio. Será la política económica la que defina el mayor o menor grado de reglamentación. La competencia está regulada por el derecho, y es un proceso dinámico cuyo grado de apertura depende de una decisión política. Téngase en cuenta que se trata de legislación dictada antes de la reforma constitucional de 1994, cuando en las normas de la Carta Magna no existían previsiones relacionadas con el derecho a la competencia efectiva.

\section{REGULACIÓN DE LA COMPETENCIA EN EL ORDENAMIENTO JURÍDICO ARGENTINO}

Legislar en materia de defensa de la competencia es necesario para regular que el mecanismo de toma de decisiones a través de la oferta y la demanda no se encuentre viciado, y de esa manera combatir el accionar de las concentraciones de poder económico que deriven del abuso y del privilegio, garantizando el funcionamiento eficaz y transparente del mercado.

Existen dos estándares de intervención básicos. La tradición estadounidense le asigna como objetivo principal a dicho control el evitar que se limite la competencia de los mercados. La posición europea se preocupa, en cambio, por lograr que los procesos de concentración económica no creen o refuercen una posición dominante, es decir, que se admite que los mercados sean más concentrados, siempre que esto no lleve al surgimiento de un agente económico con poderes abusivos en el mercado.

En nuestro sistema, el marco regulatorio de la defensa de la competencia aparece concretamente durante la última dictadura militar (Ley 22.262 de 1980), habiendo recibido en 1999 una actualización de sus conceptos, autoridad de aplicación y ámbito de protección (Ley 25.156, derogatoria de la anterior).

Sabemos que el mercado — aunque por sí mismo sea refractario a las regulaciones- es un agente político. Y la herramienta de la defensa de la competencia es una herida en el rostro de esa abominación regulatoria que pregona el sector más poderoso del mercado, que no ha logrado explicar debidamente la relación entre libertad irrestricta de mercado y democracia, toda vez que la aplicación de políticas de esa índole ha dejado secuelas de pobreza y marginalidad inusitadas, que han dañado el concepto de la democracia y republica con mayor intensidad que el autoritarismo político, sobre todo por haber sido implementadas dentro de regímenes democráticos. Y aun así, hemos hablado en los últimos tiempos de verdaderos golpes de mercado, definiendo así a las movidas económicas de los sectores del poder, recurrentemente utilizadas para catalizar el caos y favorecer sus intereses. 
En la Argentina, las primeras leyes en la materia, ${ }^{13}$ basadas en el modelo norteamericano prohibitivo de los monopolios (leyes antitrust), no suscitaron significativos procesos sustanciados en su virtud, caracterizados por lo extenso de su trámite, y por consiguiente tampoco condenas al respecto. Alguna doctrina comercialista entendió que el no perseguir a las concentraciones de capitales de alguna manera benefició a la economía nacional, al permitir la circulación de los mismos.

La Ley de Facto 22.262, promulgada el 1 de agosto de 1980, naturalmente sin discusión parlamentaria ni consultas sociales al respecto, reconoce el fracaso de la legislación anterior (Leyes 11.210 y 12.906$)^{14}$ y se enmarca en el sistema europeo, que apunta a la mitigación de las consecuencias no queridas de las posiciones dominantes en el mercado (abuso de las mismas), sin reprimir la existencia misma de esas posiciones, a las que tolera en tanto y en cuanto no se contrapongan al interés general ni degeneren en prácticas anticompetitivas. ${ }^{15}$ Esto importa de alguna manera admitir la inexistencia de estructuras de competencia perfecta, sin olvidar los efectos nocivos de los monopolios en determinados casos, pronunciándose por una competencia efectiva.

Así las cosas, la Ley tuvo como objetivo el control de las conductas y no de las estructuras de los mercados, atendiendo a las consecuencias y no a las causas que generan dichas conductas.

El cambio también estuvo dado por no circunscribir el tema competencia a una represión de tipo penal, como las leyes anteriores, ya que de acuerdo al sistema de la Ley, esta solo aparece en última instancia previa sustanciación de sumario administrativo y en tanto se configuren los presupuestos que la misma Ley tipifica como delictivos. El régimen también incluye una sanción civil de carácter resarcitorio (artículo cuarto), que podía ser ejercida por aquellos que como consecuencia de una práctica violatoria de la ley hayan sido desplazados de su anterior posición en el mercado o hayan estado impedidos de incorporarse a él, alcanzando la legitimación para denunciar prácticas anticompetitivas inclusive a los "consumidores perjudicados por la actuación de una empresa". ${ }^{16}$

Según su mensaje de elevación (o exposición de motivos como se la llamaba en la época), la Ley tuvo como objetivo la definición de las conductas reprimidas, la estructuración de un procedimiento administrativo orientado a investigar y prevenir, y el dictado de un marco jurídico adecuado que asegure el correcto funcionamiento de los mercados.

\footnotetext{
3 La Ley 11.210 de 1923 fue varias veces modificada, pero nunca logró aplicación efectiva.

14 Ver comentario del Dr. Fargosi a la publicación de la ley. Horacio Fargosi. "Comentario a la publicación de la Ley". Anales de Legislación Argentina, XL-C, p. 2521.

15 Como apunta Fargosi (nota anterior), se tiende a "controlar el ejercicio del poder económico más que su formación".

16 Horacio Fargosi. Op. cit.
} 
Reformada en 1999 (Ley 25.156), se estructura en cuatro capítulos: ámbito de aplicación, instancia administrativa, instancia judicial y disposiciones complementarias y transitorias.

En su faceta penal, la Ley tipifica delitos de acción pública, donde esta corresponde al Estado, a través de la autoridad de aplicación. Cuenta también con medidas para reprimir contravenciones, con sanciones aplicables por dicha autoridad y susceptibles de revisión en la alzada judicial.

Su esquema es el siguiente:

Su artículo primero prohíbe la comisión de actos que limiten, restrinjan o distorsionen la competencia, o que constituyan abuso de posición dominante y de los cuales pueda resultar (o resulte) perjuicio al interés general. ${ }^{17}$ Esos actos, tras la modificación de la Ley, son anticompetitivos en sí mismos, y no requieren la existencia de prácticas concertadas comprobadas, como lo hacía la legislación anterior. En cuanto al interés económico general, el daño a la comunidad es requisito para la configuración de la conducta prohibida, en todos los casos, siendo alternativos los primeros supuestos. ${ }^{18}$ Se admite la existencia de perjuicio potencial y no efectivo, en el sentido de que sea razonablemente determinable en cada caso particular y no una simple posibilidad abstracta de lesión. ${ }^{19}$

El artículo segundo define posición dominante con respecto a un producto o servicio cuando un agente es único oferente o demandante o, sin ser el único, no tiene competencia sustancial en el mercado nacional.

El artículo tercero establece la posibilidad de los damnificados de pedir resarcimiento por daños y perjuicios ante justicia comercial, al ser víctimas de una práctica anticompetitiva.

La autoridad de aplicación es la Secretaría de Comercio, en cuyo ámbito funciona la Comisión Nacional de Defensa de la Competencia, formada por un presidente y cuatro vocales (integrada por abogados y especialistas en ciencias económicas), con jurisdicción en cualquier lugar del país donde sucedan los hechos. Esta Comisión puede realizar estudios, requerir informes a organismos públicos y privados, citar a responsables y testigos, fijar audiencias, pedir medidas preventivas a la justicia, con legitimación a tal efecto. Lleva registro de sus

17 La Cámara Nacional en lo Penal-Económico, Sala B, 9-11-98, J.A. 2000-I-330, estableció que el interés económico general "debe ser entendido como el interés de la comunidad y no el de determinado agente económico".

18 Ver Marcela Basterra. "La defensa de la competencia, las leyes antimonopolio y la Constitución Nacional". Revista Cientifica de la UCES, 1, vol. IV (2000). Otros autores toman esta necesaria afectación al interés económico general como argumento para señalar que no existen conductas anticompetitivas per se, ya que "cada acto restrictivo será juzgado para determinar si existe peligro de dañar el interés económico general. Después de analizar el acto en cuestión, las circunstancias en que se realiza y su impacto en el mercado, se determina si es ilegal o no" [Ver Jorge Otamendi. "El interés general y la eficiencia económica en la ley de defensa de la competencia”. La Ley (1999-F), p. 1087.]

19 Marcela Basterra. "La defensa de la competencia, las leyes antimonopolio y la Constitución Nacional". Revista Científica de la UCES, 1, vol. IV (2000). 
dictámenes, que participan del carácter de actos preparatorios de la voluntad administrativa en formación, y son obligatorios antes del dictado del acto administrativo pertinente (Artículo 7 inciso d), Ley 19.549), ya que las decisiones las toma el Secretario de Comercio, luego de un procedimiento administrativo previo a la instancia judicial y obligatorio, siendo la opinión de la Comisión no vinculante e irrecurrible, atento las características de los dictámenes. En ese procedimiento, el consumidor puede revestir solamente el carácter de denunciante, y en principio no es parte del procedimiento sumarial — salvo que la autoridad de aplicación decida conferirle intervención como coadyuvante- ni tampoco recibe beneficio alguno en términos de compensación. ${ }^{20}$

La Ley contiene una enunciación de prácticas anticompetitivas, no taxativa, consideradas restrictivas de la competencia, que pueden producir los efectos antes mencionados. ${ }^{21}$

a) Fijar, concertar o manipular en forma directa o indirecta el precio de venta o compra de bienes o servicios al que se ofrecen o demanden en el mercado, así como intercambiar información con el mismo objeto o efecto;

b) Establecer obligaciones de producir, procesar, distribuir, comprar o comercializar solo una cantidad restringida o limitada de bienes, o prestar un número, volumen o frecuencia restringido o limitado de servicios;

c) Repartir en forma horizontal zonas, mercados, clientes y fuentes de aprovisionamiento;

d) Concertar o coordinar posturas en las licitaciones o concursos;

e) Concertar la limitación o control del desarrollo técnico o las inversiones destinadas a la producción o comercialización de bienes y servicios;

f) Impedir, dificultar u obstaculizar a terceras personas la entrada o permanencia en un mercado o excluirlas de este;

g) Fijar, imponer o practicar, directa o indirectamente, en acuerdo con competidores o individualmente, de cualquier forma precios y condiciones de compra o de venta de bienes, de prestación de servicios o de producción;

h) Regular mercados de bienes o servicios, mediante acuerdos para limitar o controlar la

20 Juan B. Justo "El artículo 42 de la Constitución Nacional y el régimen legal de Defensa de la Competencia. Caminos divergentes". La Ley (2013-E). Cita online: AR/DOC/3366/2013

21 En el marco del MERCOSUR, el Protocolo de Defensa de la Competencia (Fortaleza, 17-12-1996, Decisión CMC 18/1996) establece que son infracciones los actos individuales o concertados, de cualquier forma manifestados, que tengan por objeto o efecto limitar, restringir, falsear o distorsionar la competencia o el acceso al mercado, o que constituyan abuso de posición dominante en el mercado relevante de bienes o servicios en el ámbito del Mercado Común, y que afecten el comercio entre los Estados parte. 
investigación y el desarrollo tecnológico, la producción de bienes o prestación de servicios, o para dificultar inversiones destinadas a la producción de bienes o servicios o su distribución;

i) Subordinar la venta de un bien a la adquisición de otro o a la utilización de un servicio, o subordinar la prestación de un servicio a la utilización de otro o a la adquisición de un bien;

j) Sujetar la compra o venta a la condición de no usar, adquirir, vender o abastecer bienes o servicios producidos, procesados, distribuidos o comercializados por un tercero;

k) Imponer condiciones discriminatorias para la adquisición o enajenación de bienes o servicios sin razones fundadas en los usos y costumbres comerciales;

1) Negarse injustificadamente a satisfacer pedidos concretos, para la compra o venta de bienes o servicios, efectuados en las condiciones vigentes en el mercado de que se trate (nota nuestra: el famoso boicot);

m) Suspender la provisión de un servicio monopólico dominante en el mercado a un prestatario de servicios públicos o de interés público;

n) Enajenar bienes o prestar servicios a precios inferiores a su costo, sin razones fundadas en los usos y costumbres comerciales con la finalidad de desplazar la competencia en el mercado o de producir daños en la imagen o en el patrimonio o en el valor de las marcas de sus proveedores de bienes o servicios. ${ }^{22}$

La Ley es aplicable a toda persona física o jurídica, pública o privada, que con o sin fines de lucro realice actividad económica en el país o en el exterior que pueda influir en el mercado nacional.

Mantiene y aclara el concepto de posición dominante (Artículo 4), que se da cuando para un producto o servicio un agente es el único oferente o demandante $o$, sin ser el único, está expuesto a competencia sustancial, o cuando por el grado de integración vertical u horizontal puede determinar la viabilidad económica de un competidor, en su perjuicio.

Establece pautas para la determinación de dicha condición, que se mide o determina según el grado en que:

* El bien o servicio es sustituible por otros, nacionales o extranjeros, y el tiempo que se requiere para ello.

22 Es la llamada política de "precios depredatorios", donde la empresa dominante busca eliminar a los competidores de esa manera (en especial y más rápidamente a los que no tienen capacidad financiera para soportar las pérdidas), para luego establecer precios altos. 
* Las restricciones normativas limiten el acceso a oferta o demanda en el mercado en que se trate.

* El grado en que el presunto responsable pueda unilateralmente influir en la formación de precios o abastecimiento del mercado, y el grado en que los competidores puedan contrarrestar dicho poder.

En materia de mecanismos preventivos, ${ }^{23}$ enuncia el concepto de concentración económica, que se produce cuando:

Se toma el control de una o varias empresas por:

- Fusión.

- Transferencia de fondos de comercio.

- Adquisición de capital accionario de otra(s) empresa(s), de manera de tener influencia determinante en sus decisiones sociales.

- Realización de acuerdos para que se transfieran activos de una empresa o se le otorgue a otra influencia determinante en su administración.

Pero, como hemos apuntado, solo se prohíben aquellas concentraciones cuyo objeto sea disminuir, restringir y distorsionar la competencia con posible perjuicio para el interés general.

Y como consecuencia de la implantación del mecanismo preventivo, estarán sujetos al llamado control de concentraciones económicas los actos que:

- Impliquen como consecuencia que la participación de una empresa sea superior al $25 \%$ del mercado relevante del bien o servicio en cuestión.

- Signifiquen un volumen negocial total de la concentración de 250 millones de dólares en el país (o mayor) o 2500 millones a nivel mundial (o mayor). ${ }^{24}$

Estas concentraciones deben ser notificadas para su examen en el plazo de siete días posteriores a la conclusión del acuerdo, ante el Tribunal de Defensa de la Competencia

23 En los Estados Unidos, en 1914, la "Ley Clayton" ya establecía el control previo de fusiones y concentraciones empresariales, perfeccionado en 1976 por la Ley Hart-Scott-Rodino. En el ámbito europeo, el Reglamento 4064/89 del Consejo de Europa le confiere a la Comisión Europea facultades de análisis de las concentraciones, desautorizarlas, separar empresas concentradas, aplicar multas, etcétera.

24 Para calcular el volumen negocial se tiene en cuenta la resultante de ventas, deducidos descuentos e impuestos, y se tiene en cuenta tanto el de la empresa en cuestión como los que esta disponga directa o indirectamente con más del 50\% del capital, con más de la mitad de la voluntad social, con poder para designar autoridades o para controlar decisiones sociales. Excepto cuando se adquiere una empresa donde ya se tenga el $50 \%$ o se adquieran acciones sin derechos o se adquieran títulos de deuda o se adquieran empresas liquidadas. 
(TDC) ${ }^{25}$ El consumidor tampoco tiene intervención alguna en estas actuaciones, ni puede lograr acceso al trámite.

La reglamentación regula también una etapa consultiva previa, ${ }^{26}$ que puede pedirse al Tribunal, y que este debe evacuar en un lapso de diez días.

Todo informe de concentración económica debe ser comunicado a la autoridad de aplicación de la Ley de Defensa del Consumidor, que puede manifestar lo que considere oportuno, pero dicha comunicación expresamente no suspende el transcurso del plazo para el pronunciamiento del Tribunal.

La legislación establece que el Tribunal fijará tres etapas sucesivas de presentación gradual de la información, que deben agotarse para poder pasar a la otra, debiendo establecerse plazos para cada una. Se deriva también a la reglamentación que emita el Tribunal cuando se constituya lo relativo al contenido de las notificaciones y documentación a presentar.

Los comunicantes pueden solicitar la confidencialidad de los datos aportados al Tribunal, cuando se entienda que la publicidad de los mismos puede afectar sus intereses, mediante petición fundada. El Tribunal debe pronunciarse en cinco días al respecto.

En relación al fondo de la cuestión, el Tribunal debe decidir en 45 días, aprobando (en forma expresa o tácitamente por silencio), poniendo condiciones para la aprobación —en su caso fijará plazo para satisfacer la condición, prorrogable por única vez ante manifestación fundada-, o rechazando. ${ }^{27}$ También el Tribunal puede solicitar la presentación o exhibición de documentación adicional, una sola vez, con efecto suspensivo del plazo en curso.

La autorización es definitiva, salvo que se acredite que la resolución fue dictada en base a información proporcionada que resulte falsa o incompleta.

Si la actividad de la empresa o de la concentración resultante está controlada por ente regulador, debe pedírsele a este un informe sobre impacto en el sector, que deberá ser fundado, en cuanto a la significación de la concentración sobre el mercado o sus efectos y correspondencia con el marco regulatorio respectivo.

25 La notificación puede ser previa y el plazo de una semana posterior se cuenta a partir de la conclusión del acuerdo, o de la publicación de la oferta de compra o la adquisición de participación controlante. Formalmente, la comunicación debe ser practicada por todas las partes intervinientes en la operación en cuestión. Están eximidas de notificar las operaciones que impliquen adquisición de empresas liquidadas, de acciones sin derecho a voto o títulos de deuda empresaria, o cuando se adquiere una empresa de la que ya se posee el $50 \%$ de las acciones. La omisión de notificar está sancionada en el Artículo 4 de la Ley.

26 Resolución 26/06 de la Secretaría de Coordinación Técnica del Ministerio de Economía (Boletín Oficial del 24-7-2006).

27 Este plazo se considera exiguo, y puede llevar en muchos casos a la aprobación automática. 
Curiosamente, el plazo para pronunciarse esta vez es de noventa días, con el efecto de interpretarse como "no objeción" en caso de silencio.

Además de la Ley 25.156, conforman el régimen de control de fusiones el Decreto 89/2001 (reglamentario de dicha Ley) y la Resolución 40/2001 de la Secretaría de Defensa de la Competencia y del Consumidor, que aprueba la guía para la notificación de operaciones de concentración económica.

Entendemos que la directriz del análisis de las concentraciones económicas debiera ser acorde al texto constitucional, en el sentido de no permitir distorsiones de los mercados, por lo que toda forma de monopolio que no sea natural o legal se encuentra prohibida a nivel constitucional. ${ }^{28}$ De no ser así, no se hubiera garantizado al consumidor el derecho de libertad de elección y su correlato de la libre competencia. Y mucho menos se hubiera dejado librada la sanción de las conductas monopólicas a la verificación de práctica anticompetitiva y perjuicio real o potencial al interés económico general, subordinando la custodia de un valor tan significativo a las variables de la casuística.

Aída Kemelmajer de Carluccii ${ }^{29}$ señala que, como contracara de los elementos competitivos, la posición dominante, en principio, se caracterizaría por tres rasgos (no absolutos, sino que dependen de las circunstancias del caso):

- La supresión de la libertad de elección de los consumidores.

- La adopción de una política industrial y de ventas por parte del oferente, independiente de las condiciones del mercado y de la conducta de los demás competidores.

- La posibilidad de determinar unilateralmente el precio.

Es importante señalar estos aspectos, desde que nuestra legislación no castiga la posición monopólica en sí misma, como hemos señalado, sino el abuso de la posición dominante.

La legislación argentina (artículos 4 y 5 de la Ley que nos ocupa) en materia de concentraciones adopta el criterio del test de "poder de mercado", ${ }^{30}$ por el cual se analiza si una concentración económica creará o aumentará la probabilidad de ejercicio del poder de mercado, ya sea en forma unilateral por parte de la nueva empresa fusionada o en forma coordinada entre las distintas empresas que participan en el mercado. ${ }^{31}$

28 "El constituyente reformador adoptó el criterio de la ilegalidad intrínseca de los monopolios económicos y los prohibió de forma genérica, porque entendió que ellos siempre tienen un impacto negativo sobre el interés económico general o - mejor aún - sobre el derecho fundamental a la libertad de elección”. Juan B. Justo. Op. cit.

29 Aída Kemelmajer de Carlucci. "Derecho de los consumidores y derecho de la libre competencia". Academia Nacional de Derecho (2000), p. 261. Cita online: AR/DOC/10932/2003.

30 Sistema adoptado en los Estados Unidos.

31 La otra forma de análisis, adoptada en la Unión Europea, es la del test de "posición dominante", donde se analiza si la operación de concentración económica creará o consolidará una posición dominante. Ambos sistemas responden a 
Por el sistema de la Ley, una fusión (de cualquier tipo) solo podrá ser objetada si se prevé que su concreción traerá aparejado un aumento de precios (creación o aumento del poder de mercado), resultando perjuicio para el interés general, es decir, solo dándose ambos supuestos. Bienestar general debe ser interpretado en el sentido de excedente de los consumidores y excedente de los productores, de modo que el bienestar agregado y los ahorros de los costos derivados de la operación de la concentración sean superiores a la pérdida de bienestar generada por el mayor poder de mercado derivado de dicha operación. ${ }^{32}$

Como ha sido dicho por el Tribunal de Defensa de la Competencia, la autoridad de aplicación conjuga el análisis económico (para visualizar los efectos que provoca una conducta en la libre competencia con relación a un mercado determinado) con el jurídico- normativo, más el estudio de los efectos de las conductas sobre los consumidores.

Al tiempo que esto se escribe, el Tribunal de Defensa de la Competencia no ha sido constituido, continuando emitiendo dictámenes la Comisión Nacional, creada por la ley anterior. Tal omisión no es ingenua, como fácilmente podrá colegirse. No obstante, el artículo 58 de la Ley vigente dispuso expresamente el mantenimiento de la tarea de la Comisión hasta tanto se cumpla con la formación del Tribunal. Tal omisión es central, en la medida que importaba pasar a contar con una autoridad de aplicación independiente del poder político en la labor de controlar el accionar de los monopolios y de los grandes grupos empresariales en la economía nacional. ${ }^{33}$

La Ley de 1999 pensó al Tribunal como órgano autárquico dependiente del Ministerio de Economía, con sede en la ciudad de Buenos Aires, compuesto por siete miembros, que incluye la participación de abogados y profesionales en ciencias económicas. Son elegidos por concurso de oposición y antecedentes, y su designación corresponde al Poder Ejecutivo Nacional, permaneciendo seis años en sus cargos, que son de dedicación exclusiva. ${ }^{34}$

Entre sus facultades y funciones, tiene atribuidas la realización de estudios, investigaciones, el pedido de informes a entes públicos o privados, convocatoria de audiencias, pedido de medidas procesales, pericias, sanciones, emisión de opiniones, recomendaciones, celebración de convenios con otras entidades. Puede intervenir también de oficio o ante denuncias de prácticas anticompetitivas o prohibidas.

preocupaciones similares, pero no son idénticos. El test de poder de mercado hace énfasis en lo macroeconómico y en el bienestar general; en cambio, el de posición dominante apunta más a proteger a las pequeñas y medianas empresas frente a la acción de una empresa más grande y más eficiente.

32 Ver reportaje al Dr. Marcelo R. D’Amore en la Revista del Colegio Público de Abogados de Capital Federal, abril de 2001, p. 35.

33 Daniel Schurjin Almenar. "Lineamientos centrales del régimen argentino de defensa de la competencia". La Ley (2013B).

34 Los miembros del Tribunal están afectados por las causales de recusación y excusación previstas en el Código Procesal Civil y Comercial de la Nación, y su remoción puede disponerse previa acusación del Poder Ejecutivo o de la Presidencia del Tribunal ante el mismo jurado que los designó, por las causales previstas en el Artículo 21 de la Ley. 
Redacta su reglamento interno. Tiene legitimación para iniciar acciones ante la justicia, y lleva a cabo inspecciones por orden judicial.

Procedimiento:

- La ley determina los requisitos de forma de las presentaciones de denuncias.

- Son parte el denunciante, el denunciado y la Subsecretaría de Defensa del Consumidor. En materia de requisitos formales de la denuncia, rige el informalismo, aunque supletoriamente no se aplica la Ley de Procedimiento Administrativo 19.549 sino el Código Procesal Civil y Comercial de la Nación.

- Previo examen de pertinencia, se da traslado de la denuncia por 10 días al responsable, y posteriormente se pronuncia el Tribunal sobre la procedencia de la instrucción.

- El plazo máximo de la instrucción es de 180 días.

- En caso afirmativo, la instrucción comienza con la fijación de 15 días para presentación de descargo y ofrecer prueba. Las decisiones en esta materia no son recurribles. El plazo de prueba es de 90 días prorrogables.

- Concluida la prueba, se dan seis días por su orden para presentación de alegatos, dictándose la resolución que agota la vía administrativa en 60 días.

- Se confiere al Tribunal legitimación para peticionar medidas cautelares ante la justicia, y en aras del esclarecimiento de los hechos puede llamar a audiencias públicas, dar intervención a entidades de usuarios o consumidores o requerir dictámenes técnicos a otras entidades públicas o privadas. Durante el procedimiento, el Tribunal puede imponer el cumplimiento de condiciones u ordenar el cese de conductas a título preventivo. También puede arribarse a compromisos conciliatorios por parte de los responsables, que deben ser sujetos a la aprobación del Tribunal.

- Dictada la resolución, esta es susceptible de pedidos de aclaratoria en un plazo de 3 días. Se prevén sanciones para la falsa denuncia.

- Las sanciones aplicables pueden ser: orden del cese de acto o conducta, multa (determinada según la perdida incurrida por los afectados, el beneficio obtenido por los responsables y los activos involucrados, y que se duplica por reincidencia), la cual puede ser establecida solidariamente con los directivos ${ }^{35}$ en casos culposos, con accesoria de

35 Directores, gerentes, administradores, síndicos, miembros del Consejo de Vigilancia, mandatarios o representantes legales que por su acción u omisión de deberes de control hubiesen contribuido, alentado o permitido la comisión de la infracción. 
inhabilitación. Se gradúa según el daño causado, la intención, el porcentaje del mercado representado, la duración de la práctica y los antecedentes del sancionado.

- Para el caso de abuso de posición dominante, puede ordenarse el cumplimiento de condiciones que apunten a neutralizar los aspectos distorsivos sobre la competencia o hasta solicitar al juez competente que las empresas infractoras sean disueltas, liquidadas, desconcentradas o divididas.

- Ello, sin perjuicio de la posibilidad del inicio de acciones de Derecho Común, por ejemplo, por los daños y perjuicios que pudiesen corresponder.

- Las resoluciones del Tribunal son apelables tanto para multas (con efecto suspensivo) como para las demás sanciones (efecto devolutivo). El recurso se presenta y funda ante el mismo Tribunal en 15 días desde el dictado de la resolución, quien debe elevarlo a la Cámara Nacional de Apelaciones en lo Civil y Comercial Federal (Artículo. 53 del Decreto Reglamentario 89/200136), o Tribunal Federal del Interior, en lugar de la Cámara Nacional en lo Penal- Económico, que era la alzada prevista en la legislación anterior. ${ }^{37}$

- El plazo de prescripción de las acciones previstas en la Ley es de 5 años.

Como hemos señalado, el Tribunal de Defensa de la Competencia no se ha constituido desde 1999 a la fecha, rigiendo procedimentalmente la Ley 22.262 anterior y la estructura de la vieja Comisión Nacional.

\section{CONCLUSIONES}

- La protección constitucional de la defensa de la competencia es un instrumento de política pública para proteger tanto a los competidores como a los intereses particulares de los consumidores, al sancionar aquellas conductas anticompetitivas que lesionen al interés económico general.

- El texto constitucional brinda elementos reguladores del funcionamiento de los mercados, a los que debe adecuarse la legislación que se dicte.

- Es necesario dotar al consumidor de un rol activo en los mecanismos de defensa de la competencia, a fin de que deje de ser un mero "destinatario reflejo" de decisiones estatales. Podría conjugarse este mejor acceso con la legitimación de las asociaciones de consumidores

36 El texto original de la Ley aludía a la Cámara Nacional de Apelaciones en lo Comercial, pero fue vetado por el Poder Ejecutivo.

37 No obstante lo expuesto, por fallo del 21-12-06 la Cámara Civil y Comercial Federal (Sala II) en autos "Luncheon Tickets S.A. s/ Apelación Resolución Comisión Nacional de Defensa de la Competencia” del 21-12-06, volvió al viejo criterio de competencia del fuero Penal Económico, según el criterio sentado por la Corte Suprema en autos "Repsol YPF GLP Envasado en la ciudad de San Nicolás s/ Recurso de Queja”. 
para iniciar los procedimientos y una regulación del derecho de acceso a la información de los mismos. $^{38}$

- La agencia estatal que resguarde el valor defensa de la competencia debe ser independiente del gobierno de turno, y técnicamente capaz de captar los fenómenos de mercado sobre los que deba actuar, y estar legitimada y facultada para llevar adelante las acciones preventivas o punitivas necesarias.

\section{REFERENCIAS}

- Basterra, Marcela. "La defensa de la competencia, las leyes antimonopolio y la Constitución Nacional”. Revista Cientifica de la UCES, 1, vol. IV (2000).

- "La defensa de la competencia en la Constitución Argentina. El artículo 42 y su ley reglamentaria 25.136”. Doctrina Judicial (2003-2).

- Cionfrini, Ernesto. "La protección de los mercados y la competencia en la Constitución Nacional". Doctrina Judicial, 2 (2002).

- Fargosi, Horacio. "Comentario a la publicación de la Ley”. Anales de Legislación Argentina, XL-C, p. 2521.

- Farina, Juan M. Contratos comerciales modernos. Buenos Aires: Astrea, 1994.

- Justo, Juan B. "El artículo 42 de la Constitución Nacional y el régimen legal de Defensa de la Competencia. Caminos divergentes”. La Ley (2013-E).

- Kemelmajer de Carlucci, Aída. "Derecho de los consumidores y derecho de la libre competencia”. Academia Nacional de Derecho (2000).

- Lutzky, Claudio. "El orden económico, las formas del mercado y la defensa de la competencia”. Temas de Derecho Industrial y de la Competencia, 4 (2000), pp. 93-108.

- Otamendi, Jorge. "El interés general y la eficiencia económica en la ley de defensa de la competencia”. La Ley (1999-F).

- Schurjin Almenar, Daniel. "Lineamientos centrales del régimen argentino de defensa de la competencia”. La Ley (2013-B). 